\title{
Targeting limited NHS resources to affect optimal care
}

Welcome to the summer edition of Clinical Medicine; the sun is now shining and, possibly unrelated, there has been a modest reduction in both admissions to the acute admissions unit and negative media around the NHS. There is a cautious air of optimism detectable in those I work with and the smile has returned to many (but not all) faces. Clearly, the problems have not all gone away but the mild reduction in pressure has allowed me at least to feel I can spend a few extra minutes with each patient, teaching my trainees and conversing with long-term colleagues about both work and life issues. There is also more time to read, and more energy for the concentration required to keep up to date.

So what do we have on offer for you to read in this edition of Clinical Medicine?

I think we offer a treasure trove of updates for the busy physician. As I stated in my last editorial, both the quality of submissions and relevance to our clinical practice is what, in my opinion, makes the contents of Clinical Medicine stand out, and what makes it such a popular offering. This edition is grounded in practical and simple solutions that may allow us to optimise patient care and I highlight a few of these below.

The mSOAR score for acute stroke patients ${ }^{1}$ potentially allows us to target those with the highest predicted morbidity simply and reproducibly at the outset of admission. While mortality rates for stroke have dropped significantly in the last 30 years, the burden of morbidity and functional disability, with its consequent demands on patients, family, friends and health and social care, are of vital importance to our patient's wellbeing, and minimising the residual functional limitation following a cerebral vascular event must be a priority. I generally have mixed views on scoring systems but, if this could be linked to an easy to use digital system that meant we didn't have to remember the exact details of the system, this could have great promise.

The advances in specialist medicine mean none of us can remain truly current in all areas, but it is often surprising how much has changed. The consequences of this knowledge gap are clearly outlined in the survey of non-nephrologists' understanding of home dialysis, ${ }^{2}$ and I suspect similar results would be found in other areas of home-delivered care outside our specialisms, such as non-invasive ventilation, remote heart failure management and probably many more. The challenge is how we find the time to embed these important specialty updates into our usual practice, to get people out of hospital and, importantly, to then keep them out unless they truly need admission.

Exclusion of significant disease, quickly and cost effectively, is also critical to the determination of those who need hospital admission and the insightful review on the new National Institute for Health and Care Excellence chest pain guidance highlights this. ${ }^{3}$ The addition of non-invasive CT coronary angiography in this pathway has now been shown to improve morbidity and, critically, mortality ${ }^{4}$ and, if implemented across the NHS, would save money in the long run. ${ }^{5}$ However, as the authors rightly point out the investment in equipment, training and personnel are not insignificant and while it might be the right thing to do, the obstacles to delivery are not to be underestimated; a finding echoed by the British Society of Cardiovascular Imaging. ${ }^{6}$

Further key summaries on non-vitamin K oral anticoagulants (NOACS - note, no longer deemed novel!), ${ }^{7}$ adrenal insufficiency ${ }^{8}$ and monoclonal antibodies, ${ }^{9}$ and the usual interesting and informative case presentations and images, ensure there is something for all of us to take away from this edition.

Finally, it is a privilege to edit this journal and I thanked my predecessor for his endeavours in my previous editorial. However, I also want to highlight and acknowledge the other, usually unsung, individuals who make it all happen; both the advisory editors and reviewers who, in their own time, and without reimbursement, ensure the quality of this publications academic content, and the RCP editorial team who ensure the finished product reliably lands on your door mat.

I wish you all a relaxing summer and hope you have time to recharge, in time for the next instalment of this valued offering.

$\begin{array}{ll}\begin{array}{l}\text { Members of the editorial board } \\ \text { Wing Commander Edward Nicol }\end{array} & \text { Dr Na'eem Ahmed } \\ \text { Editor-in-chief } & \text { Dr Michael Almond } \\ & \text { Mr Paul Belcher } \\ \text { Cono Ariti } & \text { Dr Rodger Charlton } \\ \text { Statistical editor } & \text { Dr Tim Chevassut } \\ \text { Nick Cork } & \text { Dr Tahseen Chowdhury } \\ \text { Medical student representative } & \text { Dr Albert Edwards } \\ & \text { Dr Kate Evans } \\ & \text { Dr Johanna Feary } \\ & \text { Dr Maggie Hammersley } \\ & \text { Dr Dylan Harris }\end{array}$

Prof Brian Hurwitz

Dr Nicola Jones

Dr Vikas Kapil

Dr Alexandra Lake

Dr Tom Levett

Dr Nicola Lomax

Prof Philip MacCarthy

Prof Yash Mahida

Dr Chris Marguerie

Dr Ravik Mascarenhas

Prof Martin McKee
Dr Mehool Patel Dr Gerrard Phillips Dr Roby Rakhit Dr Jo Rimmer Prof Phil Smith Dr Angela Star Prof Cameron Swift Dr Rhys Thomas Dr Duncan Wilson Dr Juliet Wright 


\section{References}

1 Thaller M, Mitchell N. mSOAR: an effective bedside stroke prognosis tool. Clin Med 2017;17:204-8.

2 Abdelaal F, Ali H, Baharani J. Is replacement modality choice knowledge important in the non-renal MDT? Experience from a single UK centre. Clin Med 2017;17:198-203.

3 Alfakih K, Greenwood JP, Plein S. The 2016 update to NICE CG95 guideline for the investigation of new onset stable chest pain: more innovation, but at a cost? Clin Med 2017;17:209-11.

4 Williams MC, Hunter A, Shah ASV et al. Use of coronary computed tomography angiography to guide management of patients with coronary disease. J Am Coll Cardiol 2016;67:1759-68.

5 National Institute of Health and Care Excellence. Putting NICE guidance into practice. Resource impact report: chest pain of recent onset: assessment and diagnosis (CG95). London: NICE, 2016. www.nice. org.uk/guidance/cg95/resources/resource-impact-report-2726121709 [Accessed 11 May 2017].
6 Nicol E, Padley S, Roditi G, Roobottom C. The challenge of national CT Coronary Angiography (CTCA) provision in response to NICE CG95 update 2016. London: British Society of Cardiovascular Imaging, 2016.

7 Millar CM, Laffan MA. Drug therapy in anticoagulation: which drug for which patient? Clin Med 2017;17:233-44.

8 Pazderska A, Pearce SHS. Adrenal insufficiency - recognition and management. Clin Med 2017;17:258-62.

9 Shepard HM, Phillips GL, Thanos C, Feldmann M. Developments in therapy with monoclonal antibodies and related proteins. Clin Med 2017;17:220-32.

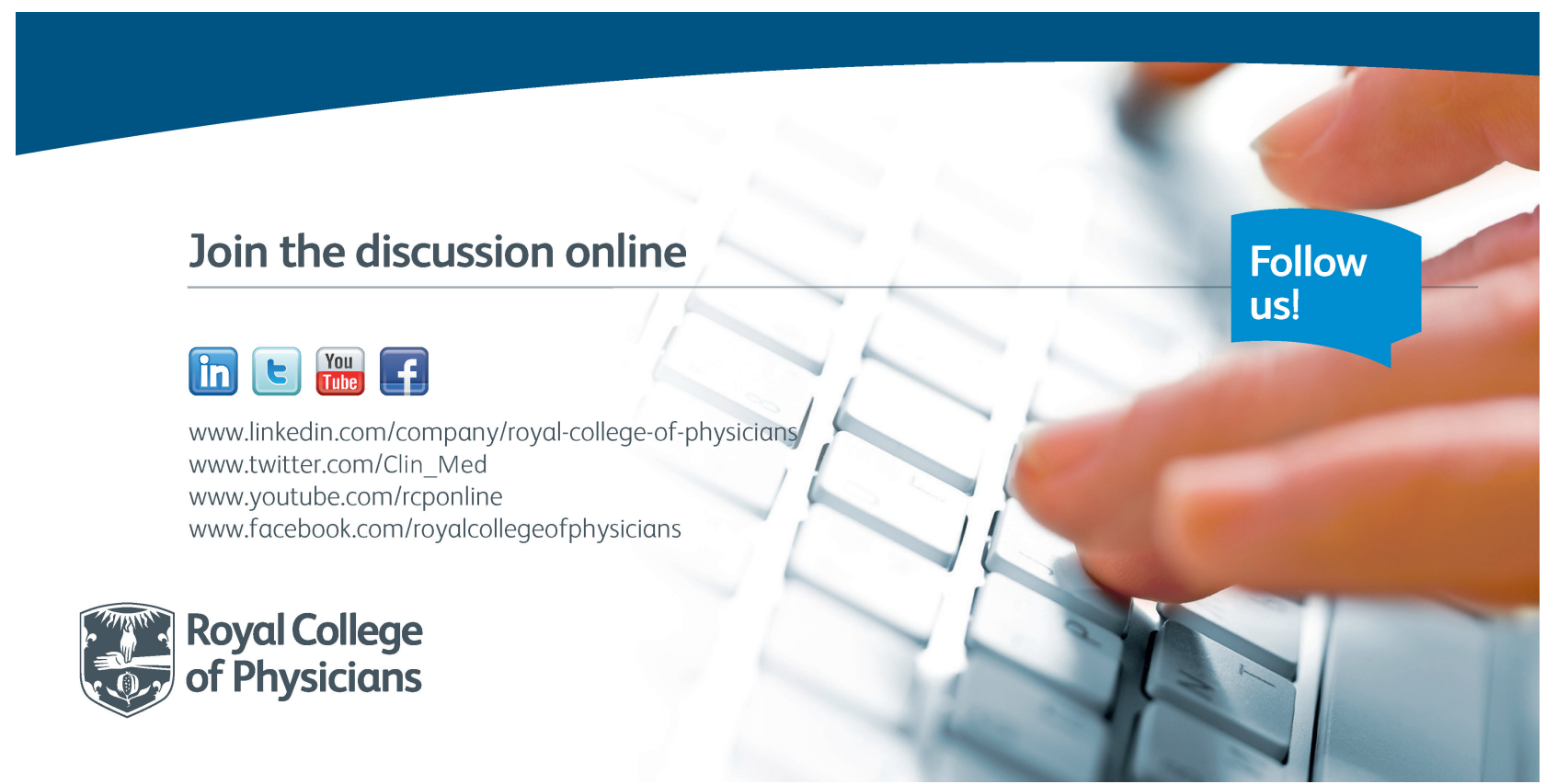

